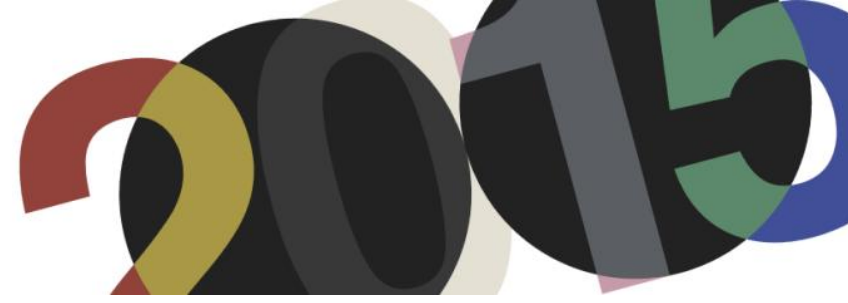

DOI: http://dx.doi.org/10.4995/LC2015.2015.1081

\title{
Reconstrucción de una pirámide borrada. Análisis de la Capilla Mortuoria encargada por Lucie Delgado-Chalbaud en Caracas, Venezuela, 1951
}

\author{
J. Alayón González, M. Dávila Cordido, O. Graterol Prado \\ Departamento de Diseño, Arquitectura y Artes Plásticas. Universidad Simón Bolívar
}

\begin{abstract}
Resumen: Este trabajo analiza, por diversos medios, el proyecto de la capilla mortuoria con dos tumbas para el expresidente militar Carlos Delgado-Chalbaud y su padre. El encargo, no realizado, fue el único que, tras varias tentativas, pudo ejecutarse en Caracas, Venezuela. Le Corbusier archivó este proyecto como un "Monument", y dentro de su trayectoria solo estuvo precedido por otro de carácter funerario dedicado al Mariscal F. Foch en la Porte Maillot de París y, posteriormente, diseñará su propia tumba en Cap Martin. Esto convierte al proyecto de Caracas, prácticamente desconocido, en un caso singular dentro de las tipologías funeraria y religiosa. La reconstrucción planteada se sustenta en la documentación conservada, el análisis histórico de las fuentes documentales, el empleo de la perspectiva clásica y las herramientas digitales para aportar precisiones y avances sobre estudios previos. En paralelo, la comparación con propuestas formales similares, enmarca el objeto de estudio dentro del legado del arquitecto. La pirámide ejemplifica la relación entre hombre y naturaleza, el "juego jugado por el hombre con los elementos cósmicos", el papel de la forma, y de las trazas reguladoras en un período en el que su racionalismo purista se abre a interpretaciones más expresivas de la forma. En el fondo de esta investigación subyace el interés por comprender el proceso proyectual de Le Corbusier y su idea de arquitectura en torno a los años 50, al tiempo que se reconstruye un proyecto prácticamente borrado.
\end{abstract}

Abstract: By several methods, this work analyzes the project for the mausoleum with two tombs for the former military president Carlos Delgado Chalbaud and his father. The unrealized commission was the only work that could have built in Caracas, Venezuela. Le Corbusier archive this project categorized as a "Monument" and in his career, it was only preceded by another funerary project dedicated to Mariscal F. Foch located in Porte Maillot in Paris, France. Only there was another funeral project: his own grave at Cap Martin. This makes this virtually unknown project in Caracas, a singular case framed within the funeral and religious categories. The proposed reconstruction is based on the preserved documentation, historical analysis of various documentary sources, the use of classical perspective and digital tools to provide clarifications and progress on previous studies. Parallel, comparisons with similar previous and subsequent formal proposals frames the object of study in its entire legacy. The pyramid illustrates the relationship between man and nature "the game played by the man with the cosmic elements", in a period in which his purist rationalism opens to a more expressive performances in form. In the background of this research lays an interest in understanding the design process of Le Corbusier and his idea of architecture around the 50's, while a virtually erased project is restored.

Palabras clave: Le Corbusier; capilla; Caracas; análisis; reconstrucción; pirámide. Keywords: Le Corbusier; mausoleum; Caracas; analysis; reconstruction; pyramid.

\section{Introducción. La pirámide borrada.}

Según explica Alejandro Lapunzina en su texto "La Pirámide y El Muro: notas preliminares sobre una obra inédita de Le Corbusier en Venezuela", el arquitecto suizo seleccionó el proyecto de capilla mortuoria en un borrador con el contenido del número 5 de su Cuvre complète. Nombrado como “Monument Delgado Chalbaud", el proyecto de Caracas hubiese cerrado este volumen, que terminó recogiendo obras tan

\footnotetext{
${ }^{1}$ En Massilia. Anuario de estudios lecorbuserianos. Barcelona: Fundación Caja de Arquitectos, 2002, № 2002, pp. 148-161.
} 
significativas como la capilla de Ronchamp, la nueva ciudad de Chandigarh con sus edificios más representativos o la Unidad de Habitación de Marsella. También están incluidos el Modulor y su obra "Plástica y Poética" a través de pinturas, murales, esculturas y tapices. Sin embargo, nos parece más relevante el que hubiese compartido páginas con la casa del Dr. Curutchet —única obra en el subcontinente- y el "Plan de Urbanización de Bogotá", cuya finalización coincidió con el proyecto venezolano.

Las razones por las que fue finalmente descartada de la edición y que la copia del proyecto correspondiente a su taller haya desaparecido de su archivo se desconocen, pero la obsesión archivística de Le Corbusier alimenta diversas teorías basadas en causas más premeditadas que la perdida casual del material. No obstante, el hecho de que se conserve algo de ese proyecto descarta, a nuestro parecer, una acción consciente por eliminar u ocultar solo parte de la documentación.

Existe la posibilidad de que Jean-Claude Mazet, su ayudante en este proyecto y con quien sostuvo una tensa relación que desembocaría en un reclamo de honorarios mayor al pautado inicialmente, pudo haber sido quien conservara la copia del proyecto. Sin embargo, de haberse roto totalmente las relaciones entre ellos dos, parece poco probable que Le Corbusier hubiese incluido las observaciones que le hizo el arquitecto asistente sobre su Modulor, publicadas en su segundo volumen de $1955^{2}$. Otra hipótesis sostenida por Lapunzina, hace referencia a las confusas condiciones del asesinato del Coronel Carlos Delgado-Chalbaud, e incluso su reputación y trayectoria como político ${ }^{3}$.

Lo único seguro es que el material perdido lo constituyen 6 láminas -aunque Le Corbusier enumera 8 documentos- según la carta ${ }^{4}$ que anuncia a su cliente el envío, en correo aparte, de la carpeta del anteproyecto con la siguiente información:

DEL $\mathrm{n}^{\circ}$ 4344. Escala $5 \mathrm{~mm} / \mathrm{m}$. Plano de situación

$\operatorname{DEL~}^{\circ}$ 4345. Escala $1 \mathrm{~cm} / \mathrm{m}$. Vista a vuelo de pájaro de la capilla y de su entorno.

DEL n ${ }^{\circ} 4346$. Escala $1 \mathrm{~cm} / \mathrm{m}$. Planta baja con la disposición del altar y las tumbas.

$\operatorname{DEL~n}^{\circ}$ 4347. Escala $1 \mathrm{~cm} / \mathrm{m}$. Alzado de la capilla y su entorno desde la vía de acceso.

DEL $\mathrm{n}^{\circ}$ 4348. Escala $1 \mathrm{~cm} / \mathrm{m}$. Vista de la capilla desde el otro camino y dentro del recinto.

DEL $\mathrm{n}^{\circ} 4349$. Escala $1 \mathrm{~cm} / \mathrm{m}$. Perspectiva interior de la capilla sola.

DEL no 4350 . Escala $1 \mathrm{~cm} / \mathrm{m}$. Perspectiva de la capilla en el interior del cercado.

DEL $n^{\circ} 4351$. Trazos reguladores que determinan la armonía del proyecto.

De estos planos solamente se conservan cuatro fotografías de la carpeta abierta mostrando las cuatro primeras láminas y dos dibujos que podrían corresponder al 4349 y 4350. De las dos vistas de la lámina 4348 y de los trazos reguladores que contendría la última, solamente quedó el boceto de preparación del documento 5 .

\footnotetext{
${ }^{2}$ El texto al que hacemos referencia dice: "El Sr. Jean-Claude Mazet, arquitecto, observa una grave falta debida a mi ignorancia (que, por desgracia, ;se extiende a todos los dominios!)", a continuación enumera las observaciones que le hace Mazart. Ver: Le Corbusier: El Modulor 2. Buenos Aires: Editorial Poseidón, 1962. pp. 40-41.

${ }^{3}$ Ver el apartado: "Carlos Delgado-Chalbaud y los acontecimiento que motivaron el proyecto", en: Lapunzina, Alejandro: "La Pirámide y El Muro" pp. 149-151.

${ }^{4}$ FLC I2-08 32.

${ }^{5}$ FLC I2(8)52. En otro documento, el FLC I2-08 34, Le Corbusier deja una nota para Mazet en donde le solicita: "Faire le dossier Delgado-Chalbaud en photostat avec spirales en 2 exemplaires : un pour l'atelier et un pour le client".
} 


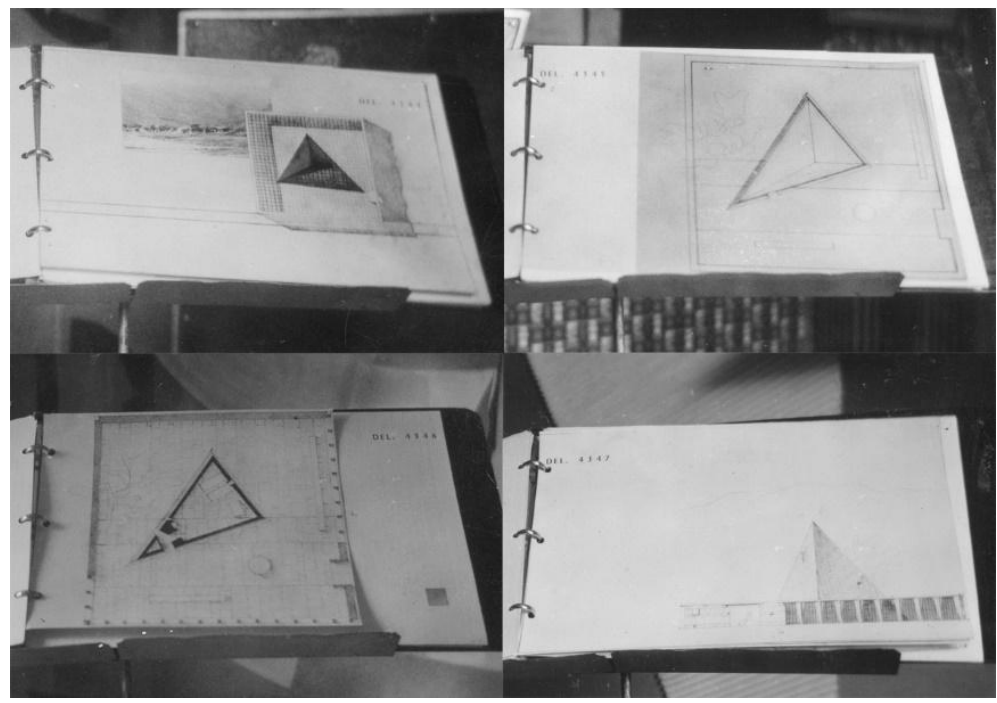

1. Fotografías de las cuatro primeras láminas del anteproyecto: DEL n ${ }^{\circ} 4344$, DEL nº 4345, DEL n 4346, y DEL nº 4347. (OFLC-ADAGP

Del lado venezolano es probable que un simple descuido o menosprecio haya llevado la carpeta que viajó a Venezuela, vía Nueva York ${ }^{6}$, al fondo de un basurero. Ni la familia Delgado-Chalbaud — que recientemente ha constituido una fundación-, ni el Archivo del Palacio de Miraflores (sede presidencial) ${ }^{7}$, ni la Biblioteca Nacional, ni el Archivo General de la Nación, todas instituciones consultadas para esta investigación, poseen dicha copia o noticia alguna al respecto. La poca tradición archivística venezolana y la destrucción accidental de parte de depósitos documentales tan importantes como el del Ministerio de Obras Públicas, nos dan pocas esperanzas de poder acceder a esa documentación que ha quedado perdida en el tiempo, entre París y Caracas.

El dossier I2-08 archivado en la Fondation Le Corbusier, conserva los documentos sobrevivientes ya mencionados, pero en su web tampoco enumera la capilla mortuoria entre la selección de sus obras no construidas (ver: Works $\rightarrow$ Architecture $\rightarrow$ Projects) $^{8}$, pudiendo estar listada tras el "Plan Urbano de Bogotá" o los proyectos frustrados de Chandigarh de los años 50.

Nuestro estudio no pretende agotar el tema, pues los datos existentes solo permiten hacer algunas precisiones y ampliaciones sobre la "notas preliminares" de Lapunzina. Las hipótesis planteadas han tratado de demostrarse con distintos métodos y apoyándonos en el resto de la obra lecorbuseriana, buscando enfocar el borroso anteproyecto que el arquitecto dejó. El ejercicio de su reconstrucción se plantea en el marco de su arquitectura de posguerra, sin descuidar sus precedentes racionalistas, de los cuales la capilla tetraédrica es un ejemplo tardío que marca, justamente su transición de una concepción de la forma pura a una expresiva.

Intencional o casualmente, esta pirámide ha sido borrada, a pesar de ser uno más de los proyectos malogrados en el nuevo mundo. La capilla hubiese sido levantada en un espacio geográfico tropical, cerca del ecuador, a medio camino entre la argentina Casa Curutchet (1949-53) y el estadounidense Carpenter Center (1960-63), ambos

\footnotetext{
${ }^{6}$ Por intermediación de la Sra. Douce Correa, a cuya dirección en Nueva York hace el envío Le Corbusier.

${ }^{7}$ Durante el desarrollo de esta investigación, en el segundo trimestre de 2015, el Archivo del Palacio de Miraflores se está trasladando al Archivo General de la Nación por labores de conservación, no obstante, en consulta verbal realizada a su director, el Lic. Marcos Fuenmayor, el 29.04.2015, nos aseguró que en dos ocasiones anteriores había realizado la misma búsqueda sin éxito.

${ }^{8}$ Solo aparece en el apartado "Architecture-Alphabetical Index", en el bienio 1951-53, con los documentos $8 \rightarrow 52$ bajo el nombre: "Caracas - Vénézuela. Chapelle commémorative pour les généraux Delgado et Chalbaud - 1951".
} 
extremos continentales y templados de sus dos obras americanas construidas. En cualquier caso, este trabajo redibuja y reconstruye la capilla para analizar el papel que tuvo en el contexto general de su obra, pues la pirámide caraqueña no fue ni la primera, ni la última que Le Corbusier diseñó.

\section{Las pirámides de Le Corbusier.}

\subsection{Arte.}

En sus pinturas de los años 20, los cuerpos geométricos simples que admiraba de la estética ingenieril los vemos representando botellas, vasos, copas, pipas, etc., conectados, superpuestos y, por supuesto exquisitamente calculados. Esas formas se organizan en base a relaciones geométricas que buscan una armonía perfecta. Las pirámides estaban en su lista de las grandes formas primarias, cuya imagen es "clara y tangible", por tanto, "formas bellas"10. No obstante, no aparecen de una manera explícita en los cuadros de esta época, solo las figuras cónicas son una aproximación. Nature morte du Pavillon de l'Esprit Nouveau, de 1924, o Trois bouteilles, de 1926, son dos pinturas en donde estas figuras aparecen en vista axonométrica evidenciando su base circular. Una representación frontal, sin profundidad ni sombra, podría confundirla con un triángulo o una pirámide.

En la década siguiente, en composiciones más planas como Adieu Von, 1932-1939-1957, pinta figuras triangulares, algunas de ellas contiguas, construyendo la imagen de un volumen piramidal irregular, también en proyección frontal. Pero es en la década del 50, coincidiendo con la construcción de las pirámides que estudiaremos, con obras como Taureau IX, de 1954 y Taureau X, de 1955, donde estas figuras se representan de modo más claro y, al mismo tiempo, complejo, debatiéndose entre agrupaciones de triángulos o pirámides, a veces vistas en planta o con caras sombreadas de colores distintos. El pintor Le Corbusier las representa como simples figuras de color plano o con gradaciones de colores distintos, ocasionalmente remarcadas por líneas negras que establecen claramente sus límites. Todavía en 1962, en Composition avec lignes géométriques jaunes, oranges, bleues, figuras similares definidas por estas líneas negras, son dibujadas superpuestas a otras triangulares de colores que no coinciden en todos sus lados. En soportes como la puerta de Ronchamp también son recurrentes estas formas y $\operatorname{trazos}^{11} \mathrm{y}$ en los tapices para Chandigarh, la balanza de la justicia equilibra dos triángulos de distinto tamaño.

\subsection{Arquitectura.}

\subsubsection{Talleres de Arte. La Chaux-de-Fonds, Suiza.}

En un ejercicio temprano de búsqueda formal purista, los "Talleres de Arte" para su ciudad natal, CharlesEdouard Jeanneret empieza a materializar las influencias filosóficas y estéticas de Hippolyte Taine, quien defendía las formas clásicas como las más puras y simples. En este edificio que reuniría las enseñanzas de las artes y los oficios, el joven Le Corbusier persigue un equilibrio formal, absoluto y perfecto, en donde la pirámide es el centro de la composición escalonada. Algunos autores asocian el misticismo artístico de Le Corbusier con las lecturas de John Ruskin o el propio Taine y sitúan a "Los Grandes Iniciados" de Eduardo Schuré (1908),

\footnotetext{
${ }^{9}$ Le Corbusier: Hacia una arquitectura. $2^{\mathrm{a}}$ ed. Barcelona: Poseidón, 1977. p. 16.

${ }^{10}$ Ibíd.

${ }^{11}$ Fragmentos de estas obras pictóricas han sido reproducidas en algunos muebles del Pabellón Suizo, en la C.I.U.P.
} 
como obra fundamental en la formación del joven Jeanneret que vería los viajes iniciáticos y el legado pitagórico como el destino ineludible para afrontar un camino plagado de incomprensiones y de soledad en la búsqueda de la belleza. Probablemente en esas y otras lecturas sobre el arte antiguo, estaba el germen de su fascinación por la figura piramidal que brotaría en la década de los 50 con toda su carga histórica y simbólica.

\subsubsection{0 - 1955. Capilla Notre Dame du Haut. Ronchamp, Francia.}

El proyecto de esta capilla está íntimamente ligado al de Caracas, pues la venezolana se desarrolla en paralelo a la francesa, iniciada un año antes. Aunque la primera piedra en Ronchamp se coloca el 4 de abril de 1954, ya en los bocetos del carnet de Le Corbusier en su primera visita a la colina, durante la primavera de 1950, aparece el pozo lleno de volúmenes que recoge las aguas de la cubierta principal en la cara de poniente, por medio de una gárgola ubicada exactamente en el eje longitudinal del edificio ${ }^{12}$.

La relación más evidente es, precisamente, la utilización de dos pirámides, muy esbeltas, dentro del pozo ovoide y a nivel del suelo. A diferencia del resto de pirámides analizadas que se encuentran elevadas, en Ronchamp y en Caracas, las pirámides establecen relaciones claras de escala humana. Por la simultaneidad de los dos procesos de proyecto, Le Corbusier consulta al Padre Reverendo Couturière, de Ronchamp, sobre los aspectos rituales de la capilla tropical, y serán las "normas" del cura francés las que se tendrán en cuenta en los planos definitivos, que nunca llegaron a realizarse ${ }^{13}$.

Un tercer aspecto a considerar, sería el apilamiento en forma de zigurat, ordenado por Le Corbusier, con el excedente de piedras de la demolición de la antigua capilla de Ronchamp ${ }^{14}$. Aunque no se trate de una pirámide de cuatro o cinco caras es oportuno analizar su disposición en el conjunto de la colina de Ronchamp, pues no se encuentra dentro de un recinto claro como el resto de ejemplos.

Por último, Le Corbusier debió encontrar un sitio adecuado dentro del universo moderno y controlado para elementos que escapaban a su diseño en ambos casos. En Ronchamp, para la imagen tallada en madera de la Virgen de Notre Dame du Haut (finales del s. XVII) ${ }^{15}$, y en Caracas, para el vitral de Beauvais con la imagen figurativa de la Virgen de Coromoto que la Sra. Chalbaud poseía previamente y que pidió incluir en la capilla ${ }^{16}$.

\subsubsection{Capilla Mortuoria. Caracas, Venezuela.}

Así como el proyecto no llegó a concluirse, su nombre tampoco llegó a estar claro. Designaciones como Chapelle mortuaire, tal como definió el encargo Lucie Delgado-Chalbaud; Chapelle Funéraire, como aparece en los documentos del taller; Pyramide, como la llama Le Corbusier en su memoria, Monument Delgado Chalbaud, como se hubiese publicado en su Euvre Complète; o Chapelle commémorative pour les généraux

\footnotetext{
${ }^{12}$ Raramente se representan este pozo y sus cuerpos en los planos de la planta baja, mientras que suelen ser protagonistas de las imágenes tomadas a la fachada oeste, donde el sol de la tarde exalta el juego de estos volúmenes bajo la luz.

${ }^{13}$ Esta entrevista la menciona Le Corbusier en su carta a Lucie Delgado-Chalbaud del 26 de julio de 1951. FLC I2-08 33.

${ }^{14}$ Más tarde, terminaría convirtiéndose en monumento conmemorativo a los franceses caídos, y bautizada como "Pirámide de la Paz", para lo que Le Corbusier proyectó una columna con una paloma.

${ }^{15}$ Salvada por los zauvos antes de que los bombardeos de 1944 destruyeran la capilla original.

${ }^{16}$ Este tema pudo haber sido un motivo de desacuerdo entre arquitecto y cliente. De manera tangencial, Le Corbusier da a entender que él diseñará "el vitral solicitado", por lo que Lucie debe recordarle que el vitral existe y debe incorporarse a la capilla, dejando abierta la posibilidad de que él diseñe otros. FLC I2-08 33. Más adelante, Lucie le pregunta si cree que estos nuevos vitrales deberían representar los personajes difuntos, para lo que ofrece enviar fotografías de su padre y suegro, los cuales "podrían eventualmente ser estilizados". FLC I2-08-36.
} 
Delgado et Chalbaud, como lo lista la web de la Fondation Le Corbusier, son denominaciones para el mismo proyecto. Como sea, la de Caracas es una pirámide más de la tradición funeraria y una de las primeras del arquitecto suizo, quien acepta el encargo bajo la condición de que un arquitecto asistente, bajo su tutela, sea quien desarrolle el proyecto.

Como ya comentamos, Jean-Claude Mazet, arquitecto francés, que acababa de finalizar estudios de posgrado en la Universidad de Harvard, sería el encargado de delinear la tumba de los Delgado-Chalbaud. Al final, Le Corbusier, le hace saber a Lucie que se ha involucrado personalmente bastante en el proceso, aportándole "un cuidado extremo" ${ }^{17}$ arrastrado por el entusiasmo que le causó el proyecto, afirmando "haber alcanzado una expresión arquitectural de notable dignidad" ${ }^{, 18}$, con la pirámide recubierta de cobre dentro de un recinto pétreo.

La solicitud de la Sra. Chalbaud fue recibida el 19 de marzo de 1951 y el 4 de abril siguiente Le Corbusier contesta que podría afrontar el proyecto si ella acepta las condiciones ya expuestas. Lucie da su visto bueno en carta fechada el 28 de ese mismo mes, correspondencia recibida en París el 9 de mayo. Sin embargo, pasan cuatro meses exactos desde la recepción del encargo hasta que Le Corbusier cita a Mazet para el jueves 19 de julio por carta enviada de su secretaria dos días antes ${ }^{19}$. Seguramente para ese momento Le Corbusier ya habría resuelto el diseño en sus grandes trazos. Así pues, al jueves siguiente, 26 de julio, el anteproyecto está listo para ser enviado a Caracas. Ese día, probablemente, haya sido el último que Le Corbusier le dedicó a la capilla venezolana ${ }^{20}$, pues en paralelo debía seguir pensando, entre otros proyectos, en Ronchamp y Chandigarh.

\subsubsection{Convento Sainte-Marie de la Tourette. Eveux-sur-l'Arbresle, Francia.}

En el caso del convento, la pirámide no se encuentra a ras de suelo, ni sobre la cubierta. El Oratorio de los Novicios, que es el espacio que cubre, es la suma de una estructura de dos pantallas intersectadas, en forma de cruz latina, sobre la que se apoya un cubo, y sobre éste, la pirámide. Aunque los tres niveles conforman una unidad — quizá evocando las torres románicas características de la arquitectura monacal, específicamente la de Le Thoronet que fue visitado por Le Corbusier expresamente-, cada elemento mantiene su identidad. Externamente, el arquitecto reduce la base de la pirámide para que se entienda la diferencia de los cuerpos geométricos y para disponer una canal que recoge las aguas de lluvia. Internamente, las cuatro paredes del cubo se prolongan en las caras de la pirámide que se juntan en la cúspide ligeramente inclinada hacia el centro del patio, en dirección suroeste. Ese desplazamiento del eje de la pirámide se ve compensado con el lucernario que se proyecta en la dirección contraria, buscando la luz indirecta del norte.

El Oratorio de los Novicios protagoniza el claustro del convento, aunque sin visuales claras sobre el mismo, salvo desde el balcón público de la portería. La torre cuadrada destaca en el paisaje de terrazas ajardinadas de distintos niveles de manera austera e incluso ligera a pesar de su solidez y opacidad, en un esfuerzo por tratar de elevarse hacia el cielo. También, como el lavatorio de Le Thoronet, la pirámide invade el espacio central y se puede ver, fraccionadamente, desde los pasillos del convento a través de los pans de verre ondulatoire.

\footnotetext{
${ }^{17}$ FLC I2-08 32.

${ }^{18}$ Ibíd.

${ }^{19}$ FLC I2-08 28.

${ }^{20}$ Meses más tarde intercambiaría las últimas cartas con la Sra. Chalbaud sobre la posibilidad de una posible demanda al gobierno, pero sin mencionar aspectos del diseño de la capilla.
} 
Sobre la cubierta del convento, la pirámide apenas despunta, interponiéndose a la línea del horizonte. En el interior, dos ventanas verticales, con vidrios de colores — amarillo a la derecha y rojo a la izquierda-, flanquean el altar que ocupa el centro, elevado sobre un podio de un escalón. El lucernario de la pirámide baña de luz el altar de frente, quedando de espalda al acceso.

\subsubsection{Palacio de la Asamblea. Chandigarh, India.}

En las primeras versiones del Palacio de la Asamblea, la cubierta es un plano deshabitado sobre el que, paulatinamente, irán apareciendo los volúmenes que terminarán conformando una de las imágenes más características de la nueva capital del Punjab. En una vista a vuelo de pájaro del palacio, fechada el 25 de agosto de $1955^{21}$, todavía la pirámide no es parte de la gran cubierta que brindaría la posibilidad de apreciar los fenómenos cósmicos, como la luna o el sol desde dentro del edificio. Su diseño debe producirse entre septiembre y octubre de ese año pues, los planos definitivos de la Asamblea fueron terminados en noviembre. No obstante, la idea de unos lucernarios estaba ya expresada en bocetos iniciales, justamente para explicar la conexión con el $\operatorname{cosmos}^{22}$.

La cubierta visitable, destinada a eventos, es una composición que funciona en dos escalas distintas: la del recinto de la cubierta y la del territorio circundante, sobre todo desde la explanada del Capitolio, en donde el observador puede entender el perfil claro de los volúmenes representativos de los dos niveles de la Asamblea (Cámara baja y alta) dispuestos sobre este gran techo. En la explanada, gran espacio conector de los poderes públicos, Le Corbusier construirá los "signos" y las relaciones que idearon la nueva ciudad: el Modulor, la espiral armónica, la torre de los cuatro horizontes, la Mano Abierta, etc., los cuales se ejecutarían en hormigón y "serían revestidos de color o de dorado según el caso, en madera revestida de hierro o de láminas de cobre",23, como en el caso precedente de Caracas.

La pirámide orientada al norte, cuya cara vertical y acristalada funciona como lucernario, se asienta sobre una base cuadrada que en realidad es el espacio cúbico de la Cámara del Consejo. Desde el exterior, esta base apenas más alta que el muro de fachada - al tiempo que queda escondida tras el muro perimetral permite elevar el volumen para que el arranque de la pirámide se pueda ver desde una distancia intermedia. De este recinto elevado que es la cubierta del parlamento solo emergen el casco hiperboloide de la sala de la Asamblea, la torre que da acceso al punto más bajo del casco, de manera tímida el prisma noroeste de uno de los dos accesos a la cubierta, y la pirámide que corona la Cámara del Consejo. Otros volúmenes quedan sumergidos.

\subsubsection{Museo Nacional de Arte Occidental. Tokio, Japón.}

En este último caso, Le Corbusier utiliza la pirámide también como un tragaluz que ilumina el espacio central del museo, una versión tardía de su modelo "Musée à spirale carrée". El volumen piramidal queda envuelto por otros cuatro lucernarios perimetrales que apenas permiten su visión desde fuera del edificio. Además, su ubicación en un lugar alto de la ciudad, dificulta que la pirámide pueda destacar y configurar la silueta de la caja arquitectónica y su reconocimiento desde distintos puntos de su entorno. Por el contrario, tiene un papel protagónico en el interior, en donde la pirámide vacía, llena de luz, corona la gran sala, que es el núcleo del museo. Aquí su base no cubre un espacio de dimensiones y forma similar, sino que se superpone, rotada, a la

\footnotetext{
${ }^{21}$ Publicada en: Le Corbusier: Euvre complète. Vol 6. Zurich: Les Editions d'Architecture, 1953. p. 95.

${ }^{22}$ Ver: Op. Cit. Vol. 5, p. 120.

${ }^{23}$ Ibíd. p. 153.
} 
ortogonalidad de los espacios, evidenciando el sistema estructural que queda a la vista bajo ella y potenciando el recorrido centrípeto del museo.

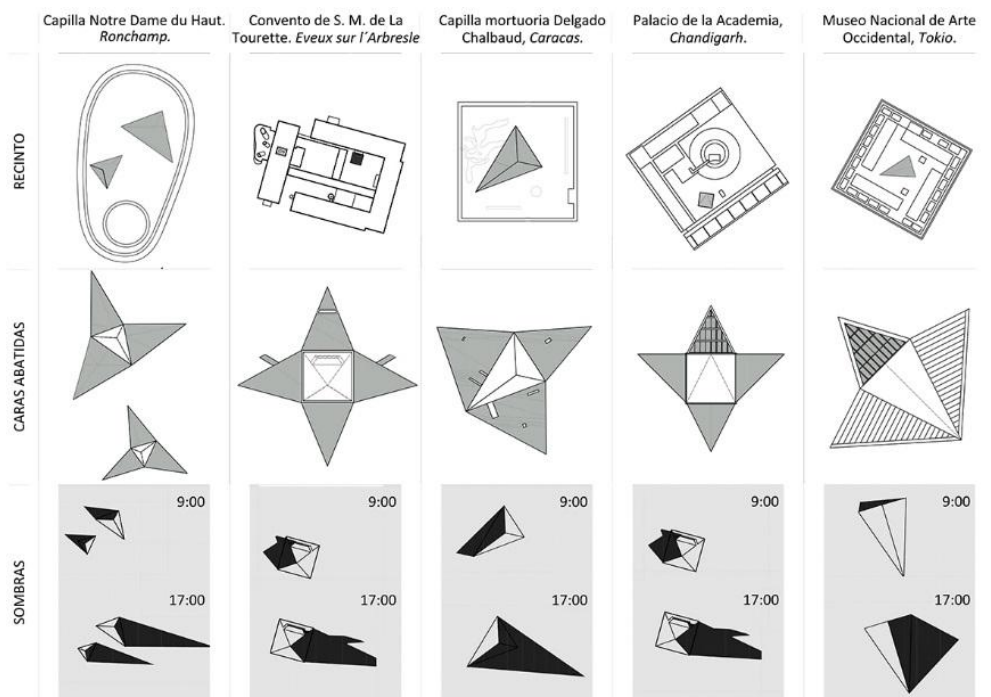

2. Cuadro comparativo de las pirámides proyectadas por Le Corbusier, mostrando: Recinto, Caras Abatidas, y Sombras de mañana y tarde respetando su latitud y longitud.
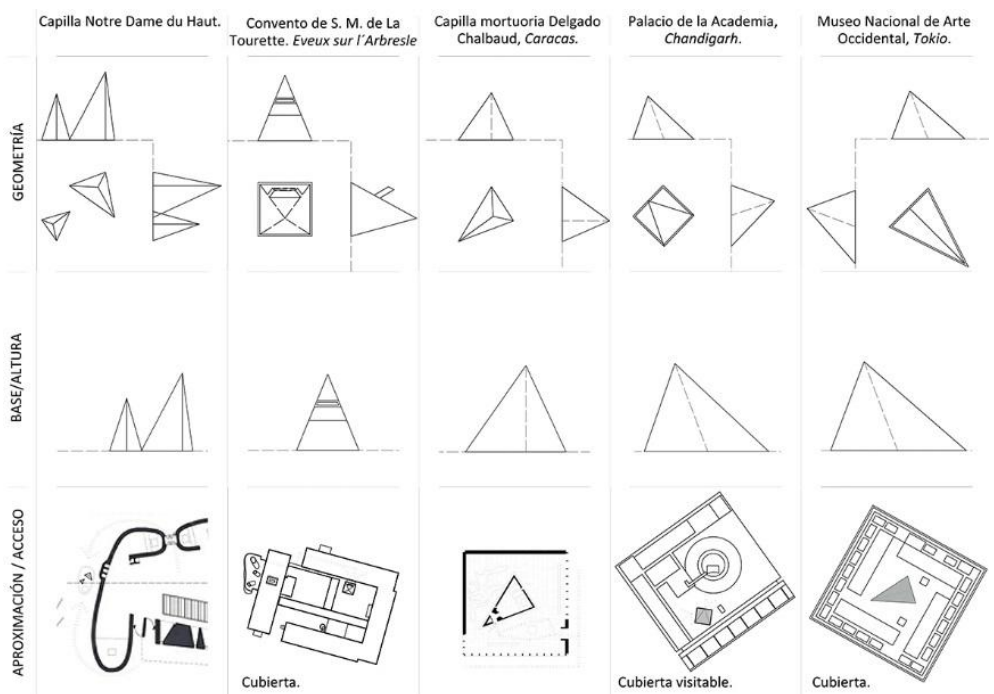

3. Cuadro comparativo de las pirámides proyectadas por Le Corbusier, mostrando: Geometría, relación Base/Altura, y Aproximación /Acceso.

\section{La pirámide reconstruida en su lugar.}

El nivel de anteproyecto en el que quedó la pirámide de Caracas nos obliga a establecer distintas hipótesis para aclarar, al menos, sus contradicciones e indefiniciones. La reconstrucción la iniciamos a partir de la documentación original conservada, es decir, las fotografías de las láminas del anteproyecto: la planta de ubicación, una planta baja, el alzado del acceso y la planta de cubierta. Una vez corregidas las deformaciones de las perspectivas de las imágenes y cuadrando la planta a una parcela de 20 x 20 metros, se delineó la misma. 
A pesar de su baja resolución, la fotografía de la planta permitió trazar con detalle el cerramiento de la parcela, el enlosado, el árbol y la planta de la pirámide. No obstante, la altura de corte horizontal no es única, ni estándar, y se superponen las proyecciones de las ventanas que están mucho más arriba, lo que dificulta el establecimiento exacto de estos vanos.

La planta redibujada certificaba que Le Corbusier, había establecido la cúspide de la pirámide en el centro geométrico de la parcela, solo nos falta determinar su altura. Para ello, escalamos la imagen del alzado hasta que el muro del recinto alcanzase los 2,26 m del Modulor, asumiendo que habría repetido la misma altura que en los umbrales de acceso - muy similares - de la casa Curutchet y de La Tourette. Con ello determinamos que la altura de la pirámide se aproximaba mucho a la 9,528 m —última medida de la serie roja lecorbuseriana ${ }^{24}$ — y así la fijamos. En paralelo, revertimos a su proyección cónica la perspectiva a mano alzada de Le Corbusier, asumiendo la misma altura de 2,26 para el muro, dando como resultado una altura de 20,28 m, lo que duplica nuestro otro dato. Descartada esta posibilidad, el resultado de esta comprobación revela la voluntad del arquitecto de proyectar una pirámide que se percibiera muy esbelta vista desde el lado sur.

Anclado ese punto central, la base de la pirámide empieza a definirse a partir de las trazas reguladoras que parten de las esquinas sur de la parcela y se cruzan en un punto sobre el eje norte-sur de la misma, a 2,26 m del muro norte. Los otros dos vértices son las medidas anterior y posterior en progresión aurea — tomadas perpendicularmente a sus linderos - en la escala Modulor. La forma resultante de estas trazas, es una pirámide irregular, pero matemáticamente definida, que apunta en su bisectriz mayor a la esquina suroeste del recinto, vértice que contiene la entrada a la capilla y el único visible desde la puerta del recinto.

Para el acceso a la capilla se repitió la altura estándar de 2,26 m, así como para los bancos 0,432 m. La mayoría de las medidas comprobables en la planta coinciden con algunas del sistema, como el tamaño de las losas de piedra del piso o los bajorrelieves de la fachada este. La forma, altura respecto del suelo y medida exacta de los vanos se definió cruzando la información de las perspectivas y la planimetría ya que solamente la ventana más alta es visible en el alzado conservado.

Comparando el despiece de todas las pirámides proyectadas por Le Corbusier, se puede observar que la de Caracas comparte con las de Ronchamp, su base triangular irregular. En el caso de Tokio, la base es un triángulo isósceles y su cara más pequeña se alza perpendicular con un ventanal, lucernario similar al de Chandigarh. Siempre que concibe los lucernarios como pirámides, éstos buscan la luz indirecta del norte, pero en Caracas, cerca del ecuador, el arquitecto abre vanos en las 3 caras de la capilla indistintamente, asumiendo además que facilitan la ventilación cruzada.

La breve descripción que envía Le Corbusier a la Sra. Chalbaud explica cómo se podría construir:

Le terrain de $20 \mathrm{~m} \times 20 \mathrm{~m}$. est entouré d'une clôture ajourée partiellement sur 2 faces, pleine sur la $3^{\circ}$ face et ajourée partiellement sur la $4^{\circ}$ face. Le dallage du sol est en pierre. Sur ce dallage se dresse la chapelle selon une pyramide à trois faces d'un tracé animé par les proportions et la mathématique, trace qui doit, à mon point de vue, conduire à une sensation rare et faire régner une harmonie.

Cette pyramide à trois faces permet de disposer l'autel et les tombeaux d'une façon subtile avec un éclairage efficace.

\footnotetext{
${ }^{24}$ En la tabla de medidas del Modulor del Atelier 35, de la Rue de Sèvres.
} 
J'ai eu un premier entretien au sujet des données rituelles de la chapelle avec le Révérend Père Couturier. Celui-ci examinera avec moi, dès mon retour de voyage, les plans d'après vos observations, les plans seront ainsi réalisés définitivement selon les règles.

Le sol et l'autel sont prévus en pierre. Les deux tombes seraient faites chacune d'une plaque de bronze fondue munie des inscriptions et symboles utiles (je dessinerai les plaques tombales). Les parois inclinées de la pyramide à l'intérieur seront de mosaïques noires et blanches; le vitrail demandé se trouvera au-dessus des tombeaux, je le dessinerai. La pyramide sera construite en béton mince de façon à éviter l'échauffement et la radiation sous l'effet du soleil. Cette pyramide serait revêtue de plaques de cuivre patinées vert de gris ; je pense que ce serait mieux ainsi (plutôt) que de faire dorer les plaques.

Sur l'espace déterminé par la clôture extérieure se trouvent deux bancs allongés de pierre et une plate-forme ronde à hauteur de siège pour s'asseoir.

Un arbre occupera une place justement désignée par les tracés. Je serais heureux de savoir quelle sorte d'arbre vous préférez de façon à donner à l'ensemble une présence vivante et amicale. En dehors de cet arbre, aucune plante ni fleurs, mais seule la simplicité du dallage de pierre du sol et l'accompagnement des montagnes que l'on voit fermer l'horizon au-dessus de la clôture prévue au projet. ${ }^{25}$

\section{La pirámide de Caracas: una sensación de armonía.}

La introducción del quinto volumen de sus obras completas ya mencionado, que resume su obra entre los años 1946 y 1952, está dedicada casi en su totalidad a su obra india y la escribió él mismo en marzo de 1953. El texto lo cierra reflexionando sobre los aspectos — como ya dijimos, él los define como signos—- "sobre los cuales son concebidos técnicamente el urbanismo y la arquitectura de Chandigarh" ${ }^{\text {"26. }}$

Ces signes sont les phases du jeu joué par l'homme avec les éléments cosmiques : homme et nature. Jeu des nombres, jeux du calendrier et de la journée solaires, jeu du soleil - sa lumière, son ombre, sa chaleur. Ce jeu fut précisément le travail de ma vie depuis toujours. Il gère, me semble-t-il, l'architecture et l'urbanisme.

Le cour ouvert, débordant, aux immensités intérieures de la réflexion, comme aussi à la grandeur toute maternelle du ciel, des plaines, des monts, des arbres, des plantes... notre univers tangible ${ }^{27}$.

Estos mismos signos son identificables en el proyecto de Caracas, cuando los edificios de Chandigarh todavía eran germinales. A través de nuestro análisis podremos evidenciar el juego de los números y del sol en torno a esta tumba, última morada y tránsito hacia el más allá, que sin embargo celebra "nuestro universo tangible". Como admite Le Corbusier, ese juego ha sido su búsqueda permanente, y si los signos — representación de algo - se potencian en los años 50, sus preocupaciones en los 20 por crear una arquitectura nueva "testimonio de un espíritu limpio" ${ }^{, 28}$, no desaparecen en su época madura. Por ello, Le Corbusier en el prefacio de la reedición de Hacia una arquitectura, en 1958, exige al editor mantener el texto original, sin cambiar nada, evidentemente para no transgredir un momento preciso de la historia pero, suponemos, también como reconocimiento a la vigencia de algunas de esas búsquedas prístinas.

\footnotetext{
${ }^{25}$ FLC. I2-08 33.

${ }^{26}$ Le Corbusier: Euvre complète 1946-1952. p.10. (Traducción de los autores)

${ }^{27}$ Ibíd.

${ }^{28}$ Le Corbusier: Hacia una Arquitectura. p. X.
} 
En la "Lección de Roma" de ese libro, Le Corbusier reproducía doblemente la Pirámide de Cayo Cestio (12 a.C.): por un lado, con una fotografía de la tumba del personaje romano atravesada por la muralla ${ }^{29}$, y por otro, su versión dibujada ${ }^{30}$, exenta, como una de las formas simples que desencadenan sensaciones constantes. Este monumento romano, por su carácter funerario ${ }^{31}$ y sus proporciones geométricas creemos que fue su principal referencia histórica para la capilla mortuoria de los Delgado-Chalbaud.

\subsection{La parcela.}

En carta escrita el 10 de marzo de 1951, sin preámbulos, Lucie Delgado-Chalbaud pregunta a Le Corbusier, si podría diseñar una capilla mortuoria con dos tumbas para su marido y suegro. El encargo es muy sencillo y concreto. La cliente solo especifica que el proyecto debe ser "sobrio y austero" 32 para poder ofrecerlo como alternativa a otros "de mal gusto" ${ }^{\text {33 }}$ que el Gobierno está estudiando, por lo que considera este encargo como urgente. En la segunda carta, fechada el 28 de abril de ese mismo año, la Sra. Chalbaud acepta las condiciones del encargo, y envía una fotografía del terreno, especificando que sus dimensiones son de 20 x 20 metros, aunque su superficie no debería ser ocupada en su totalidad por la construcción de la capilla.

De esta imagen del Cementerio General del Sur de Caracas, solo se conserva la reproducción que acompañaba el "Plano de situación", en escala 1:200 de la lámina "DEL n4344". Se trata pues de la fotografía de una fotografía. En esta imagen, con muy poca definición, se intuye la parcela a través de dos sombras lineales que podrían ser el desnivel de la acera que conforman una esquina. En primer plano, todo está vacío y las pocas construcciones que se pueden adivinar se encuentran muy al fondo. Estas siluetas se recortan contra una masa vegetal, detrás de la cual una masa blanca asemeja un volumen horizontal con una torre.

\footnotetext{
${ }^{29}$ Ibíd. p. 24.

${ }^{30}$ Ibíd. p. 128.

${ }^{31}$ La larga tradición funeraria asociada a las pirámides es un argumento evidente en la elección de esta forma geométrica. Y dentro de esta tradición existen distintas versiones de la figura apuntada. La pirámide de Roma guarda una relación más estrecha —en sus proporciones - con las pirámides nubias de Meroe, al norte de Sudán o las egipcias de Deir el-Medina, que con las clásicas de Guiza. La pirámide de Caracas que Le Corbusier dibuja en sus perspectivas también persigue una esbeltez similar.

${ }^{32}$ FLC I2-08 17.

${ }^{33}$ Ibíd.
} 


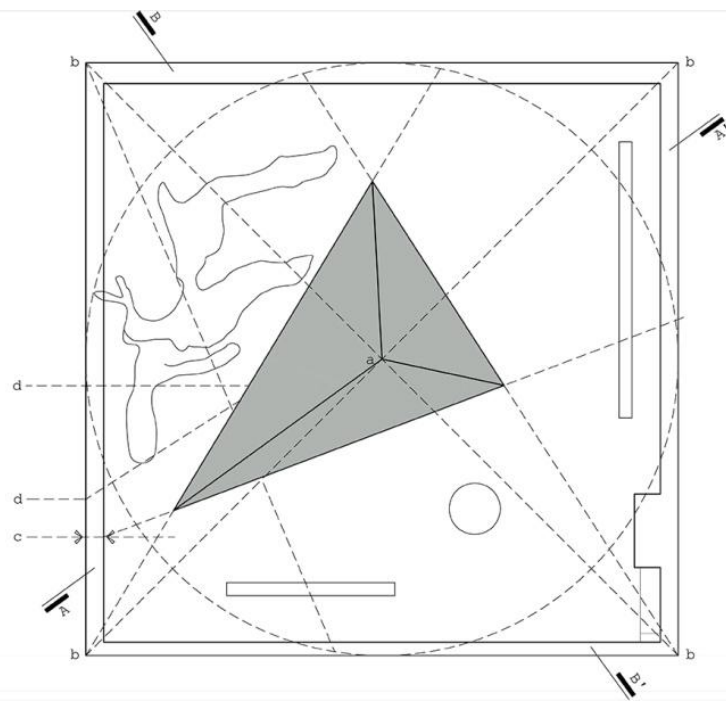

4. Planta de cubierta y trazas reguladoras.

En el plano de situación, el dibujo define solo una vía principal, con un ancho sin determinar, pero con una acera sobre la que se alinea una de las fachadas del recinto de la capilla. El acceso no está sobre esta acera sino en una cara perpendicular a ésta, en la esquina próxima a la vía que se asume como principal. No obstante, en el plano de la lámina "DEL n 4344", no se puede distinguir un acceso pavimentado. La sombra que arroja el muro de la parcela muestra un terreno irregular, sin construir y sin conformar el ángulo recto de una esquina.

Es difícil determinar si Le Corbusier obtuvo datos adicionales sobre la orientación de la parcela, pero la sombra proyectada en su plano de ubicación, generalmente representada al atardecer, nos hace concluir que la vía principal coincide con el lado sur. Otro dato que avala esta hipótesis es que justamente en el interior del vértice oriental de la pirámide, se encuentra el altar como dicta la tradición, convención que Le Corbusier ha respetado en Ronchamp, La Tourette y Firminy-Vert. Haya sido o no la orientación real de la parcela, Le Corbusier parece asumir estos puntos cardinales para su proyecto, en donde el sol de poniente proyecta una sombra que apunta al acceso del recinto y, al menos en ese momento del año, desde el acceso podrá verse el sol descender detrás de la cúspide de la capilla. Finalmente, aunque las dimensiones de la parcela donde se construyó el mausoleo aprobado por el Gobierno ${ }^{34}$, son distintas, su orientación es prácticamente la misma, por lo que no se descarta que se trate de la misma, aunque reducida ${ }^{35}$.

No se ha podido comprobar en los archivos del cementerio la titularidad inicial de esta parcela para establecer vínculos con alguna institución oficial que la haya podido ceder, ni un emplazamiento similar al de la foto. Por tanto, entre la correspondencia y documentos conservados no hay ningún dato objetivo que nos permita establecer con precisión la ubicación de la parcela dentro del cementerio más allá de lo ya argumentado. Le Corbusier asume la perfección geométrica del terreno descrito por su cliente para crear su propio universo interior determinado por la geometría.

\footnotetext{
${ }^{34}$ Proyecto del arquitecto venezolano Luís Malaussena.

${ }^{35} \mathrm{Si}$ bien el frente del mausoleo actual ronda los 20 metros de frente, su profundidad es aproximadamente 11 metros y en ninguno de sus lados existe un camino claro como para poder entender alguno de sus vértices como una parcela en esquina. Incluso, si se tratase de la parcela de la esquina más próxima de esa manzana, ésta tiene un ángulo agudo bastante acusado, descartándola como posible ubicación de la parcela cuadrada.
} 


\subsection{El recinto}

Coincidimos con Lapunzina en las referencias al templo primitivo publicado por el mismo Le Corbusier en "Hacia una arquitectura" como la primera fuente a la que acudir para entender esta capilla dentro de su propio recinto, su propio territorio. El arquitecto define este perímetro como una "clôture ajourée", una cerca calada que evoca más la presencia de un cerramiento ligero y transparente, que la del recinto amurallado que es, pese a presentar discontinuidades en algunos de los linderos.

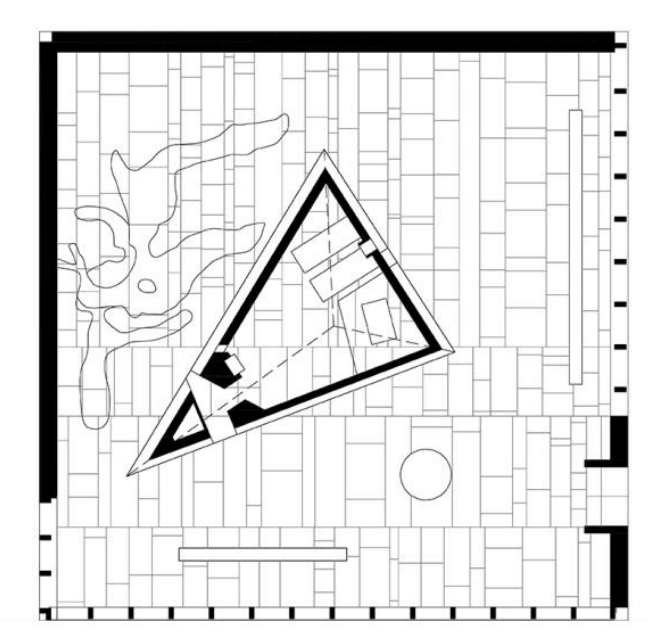

5. Planta baja de la capilla.
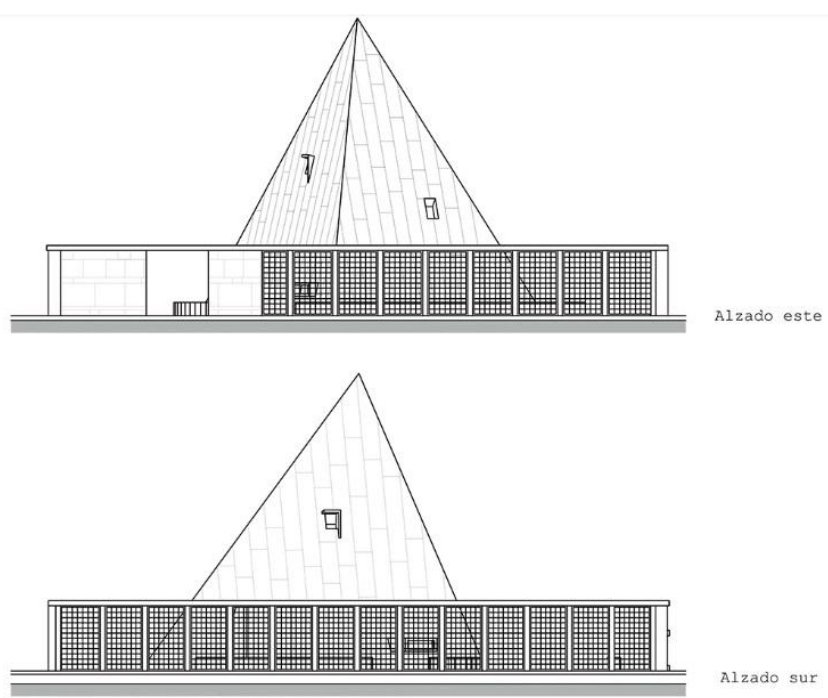

6. Alzados este y sur.

Volviendo sobre la borrosa foto de la parcela, la mayor certeza que podemos tener es que se trataba de un sector aun sin ocupar en sus inmediaciones. Un descampado sin más parámetros contextuales que las montañas que le rodean y el cielo. Y son precisamente esos dos elementos naturales los que Le Corbusier incorporará a su proyecto al no tener más detalles del lugar. 
El muro se convierte bajo estas condiciones en una primera operación arquitectónica, en la ocupación humana del entorno natural, en la materialización del encuentro entre el dentro y el afuera. Con ello, el arquitecto delimita un espacio, proyectado al cielo, en cuyo centro, según unos trazados reguladores levanta un volumen piramidal. La necesidad de dar una escala a la capilla mortuoria en un descampado, que con el tiempo se convertirá en un paisaje atiborrado de tumbas y mausoleos de las más variadas formas y tamaños, aísla al visitante del mundo terrenal, para introducirle en un espacio que se abre hacia arriba. Los bancos están dispuestos para que la pirámide siempre esté en primer término. Tras ella, el árbol, y tras él, el muro obliga a elevar la mirada hacia las montañas cercanas y al firmamento en último término.

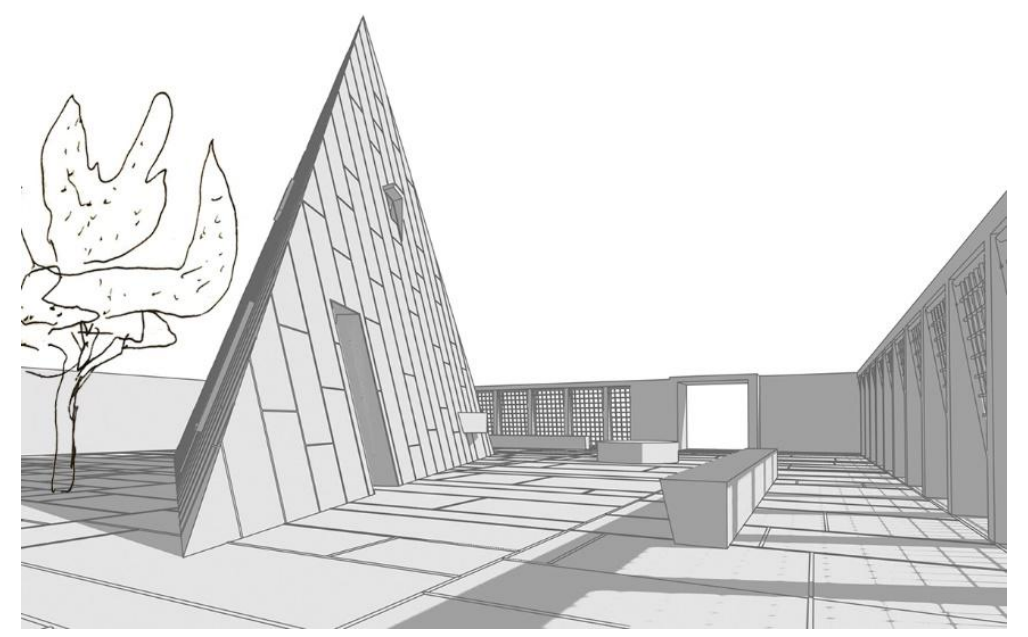

7. Vista de la capilla desde el oeste.

Aunque el recinto tiene una vocación cósmica, como en el caso de Chandigarh, el muro se comporta de manera distinta en sus cuatro costados. Al vaciar las esquinas exteriores, Le Corbusier mantiene la independencia de cada una de las caras. Hacia la vía principal, lugar donde no habría ninguna construcción próxima, es permeable y permite reconocer, a través de la cerca, la pirámide. Al naciente está el acceso, remarcado por un trozo de muro, mientras que el resto es igual que el sur: una sucesión de pilares rectangulares, cuyo intercolumnio lo ocupan vallas metálicas ${ }^{36}$ inclinadas hacia dentro. Sobre este trozo de muro una retícula de altos y bajorrelieves anuncian el vano que da acceso al recinto, a través de un umbral que marca de manera clara y dilatada el paso del exterior al interior. En el lado opuesto, el muro de poniente es el inverso, pues perfora la esquina próxima a la calle - abriendo la perspectiva sobre la vía principal - y el resto es un muro ciego, al igual que todo el lindero norte, evitando el futuro vecindario caótico de tumbas. De este modo, la diagonal que marca la dirección de la pirámide, queda reforzada por el fondo ciego que forman las caras norte y oeste, frente a las perforadas del sur y el este.

El enlosado en piedra natural define este espacio con líneas continuas norte-sur y líneas parciales este-oeste. Solamente dos trazas se interponen en sentido transversal generadas por el muro que contiene el acceso y que marcan una dirección, una especie de tapiz, que lleva hasta el acceso de la capilla. El volumen de la pirámide se asienta sobre esta trama sin interrumpirla, generando un gran dinamismo en su interior al no corresponder a ninguna de sus caras. Las líneas de las láminas de cobre que definen la superficie del volumen, paralelas entre sí

\footnotetext{
${ }^{36}$ Para la cerca perforada, Lucie comenta a Le Corbusier que al no haber mano de obra calificada, se podría, eventualmente, construir en Francia. FLC I2-08 36.
} 
y perpendiculares al suelo, refuerzan la esbeltez que perseguía Le Corbusier para su pirámide, al tiempo que su inclinación genera un contraste claro con la ortogonalidad del recinto.

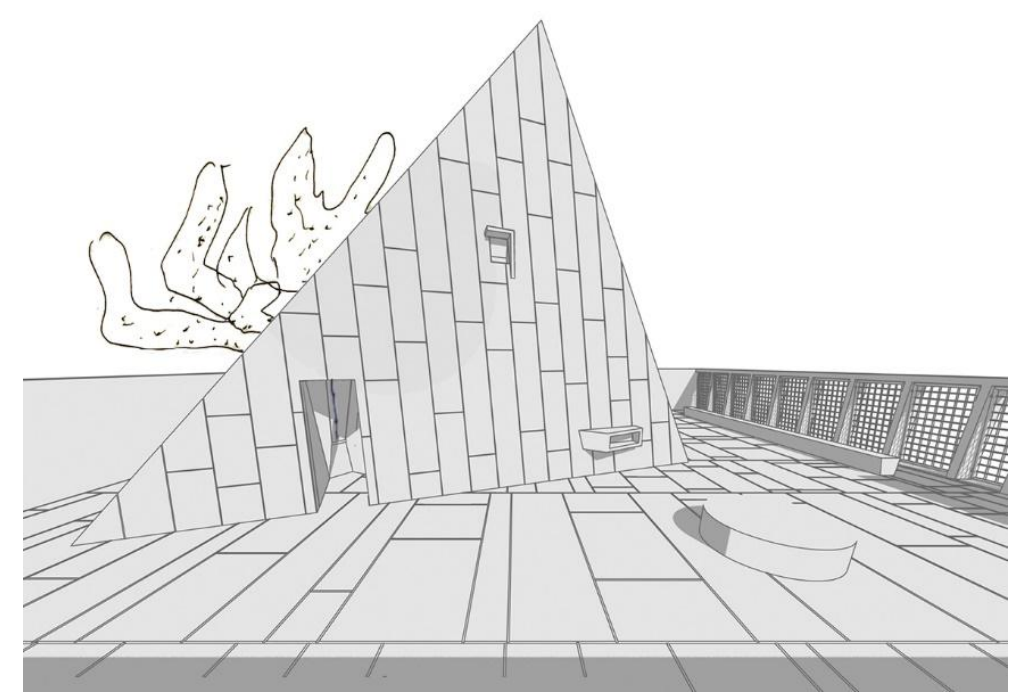

8. Vista de la capilla desde el sur.

\subsection{La pirámide}

La capilla tiene como base un triángulo escaleno, generador de un tetraedro irregular, sin ningún eje de simetría. Eje que sí tienen el resto de los ejemplos citados en este trabajo, salvo las escultóricas de Ronchamp. Esta figura irregular es, sin embargo, el resultado de unas trazas geométricas sobre el cuadrado perfecto de la parcela "que conducirán a una sensación rara y hará reinar la armonía"37. Al mismo tiempo, y aunque no lo explicita, el Modulor determina el resto de relaciones que Le Corbusier perseguía.

La respuesta sobria y austera del interior recuerda lo primitivo de la capilla paleocristiana de María in Cosmedin, recogida también en Hacia una arquitectura ${ }^{38}$. La decoración se limita solo al uso de mosaicos —otra similitud con los primeros espacios católicos-, en grandes paños de color negro y blanco que buscan potenciar el efecto dramático de las entradas puntuales de luz. En ningún documento se menciona el uso de vidrios en estos vanos y menos si serían coloreados, como en el caso de Ronchamp. La capilla tiene seis huecos, dos con altura de una puerta - uno de éstos solo es una ranura para iluminar el acceso a la capilla — , y cuatro a distintas alturas que dejan pasar la luz controladamente al interior. Le Corbusier quería una iluminación precisa para marcar la presencia sutil de los elementos de la capilla: la entrada, las tumbas y el altar, manteniendo un ambiente en penumbra que invite a la reflexión y al recogimiento.

\footnotetext{
${ }^{37}$ FLC I2-08 33.

${ }^{38}$ Le Corbusier: Hacia una arquitectura. p. 129.
} 

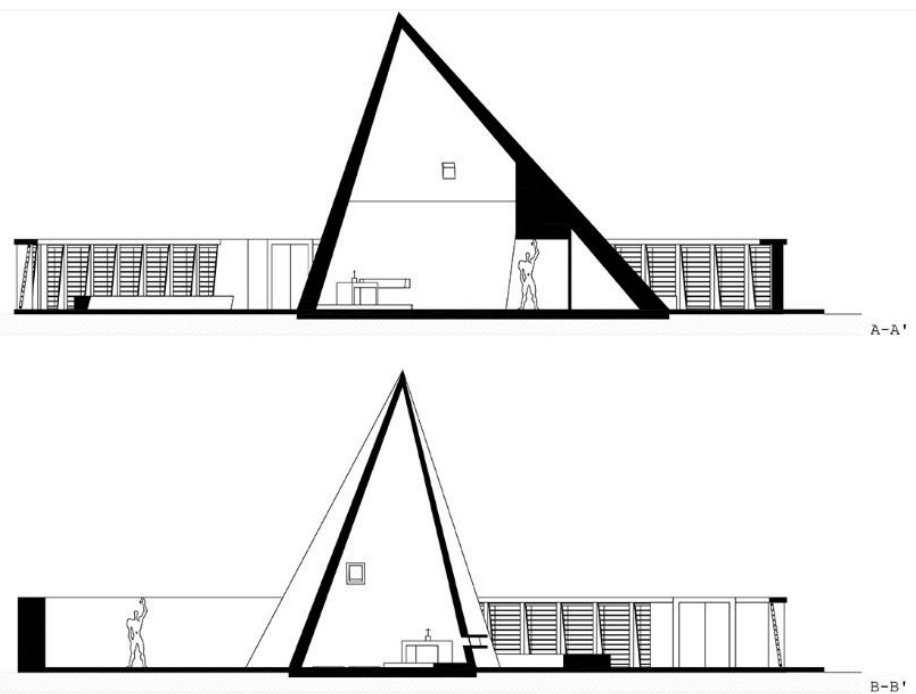

9. Secciones A y B.

El vano ubicado en la cara noreste contendría el vitral ${ }^{39}$, a 1/3 de la altura interior sobre las tumbas. A la izquierda de ésta, y a media altura aproximadamente, otro vano se abriría a la luz de poniente por la cara noroeste. En la cara sur, al costado del altar, una ventana baja y apaisada da claridad al lugar de celebración de la misa y un último hueco, a $2 / 3$ de la altura exterior, protegido del agua por una cornisa en forma de "L" invertida, cuela la luz por el punto más alto, al tiempo que evacúa el calor condensado en la parte alta de la pirámide ${ }^{40}$.

El ingreso se realiza a través del corte que secciona la punta suroeste de la pirámide. Ese espacio luminoso, dirigido a la contemplación del árbol, es sin embargo un espacio comprimido, de paso. A continuación, el espacio único, elevado y umbrío, se va revelando poco a poco, a medida que la retina se acostumbra a la poca cantidad de luz que traspasa los vanos. En la mañana, el vitral resplandecerá por el sol directo sobre su superficie de color. Por la tarde, el sol entrará por los huecos del lado oeste, pudiendo alcanzar las tumbas e incluso el altar. A la izquierda del acceso, una cavidad en el muro de gran espesor, nos hace pensar en la posibilidad de un asiento, o incluso un reclinatorio. El robusto altar reposa, como en La Tourette, sobre un escalón, mientras que las tumbas, con placas de cobre, se disponen rasantes con el suelo de piedra.

\subsection{El árbol}

Le Corbusier había dispuesto un árbol dentro del recinto, única presencia vegetal del conjunto —eliminando cualquier opción de otras plantas o flores-, el cual "daría al conjunto una presencia viva y amigable" ${ }^{41}$, pero dejaba la elección de la especie a la cliente. Ella expresaba su preferencia por el flamboyán (Delonix regia) y su espectacular floración naranja rojizo, pero admitía desconocer cuál sería el árbol más adecuado, tanto por su longevidad como por la leyenda asociada. Por esa razón, en carta del 15 de agosto de 1951, Lucie comenta a Le Corbusier que Carlos Raúl Villanueva le llevará a Francia en los próximos meses un libro sobre árboles venezolanos.

\footnotetext{
${ }^{39}$ Las dimensiones aproximadas que indica la Sra. Chalbaud son 40 x $50 \mathrm{~cm}$., pero la fotografía del mismo demuestra que se trata de una forma cuadrada.

${ }^{40}$ En el Oratorio de los Novicios de La Tourette, el vértice interior de la cúspide presenta problemas de humedades, pues la ventana queda muy por debajo de ese vértice oscuro y sin circulación de aire.

${ }^{41}$ FLC I2-08 33.
} 


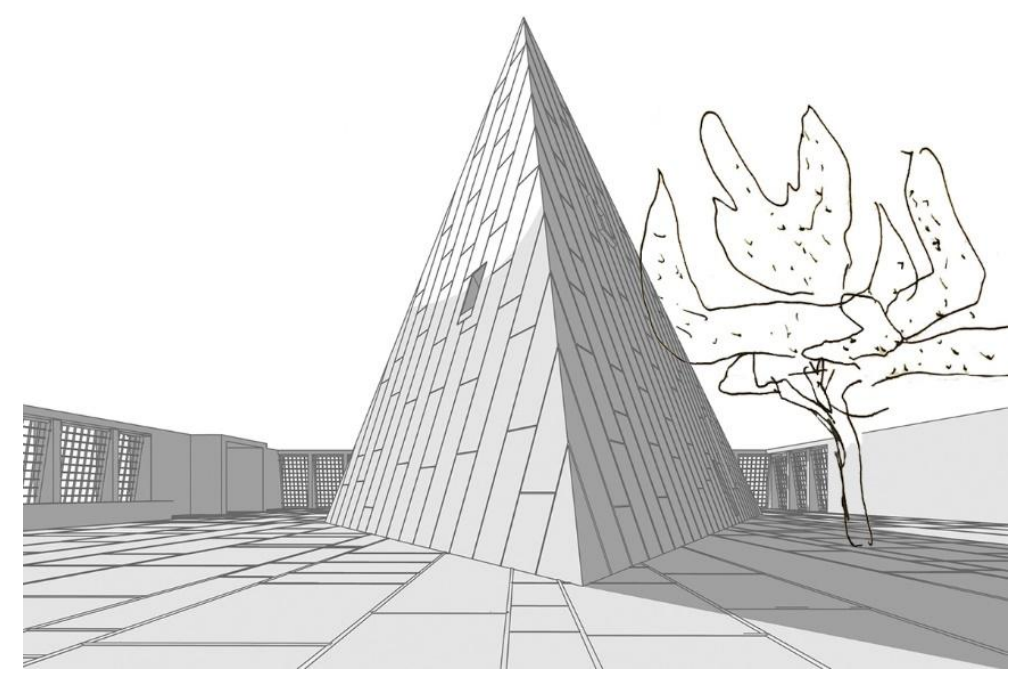

10. Vista de la capilla desde el norte.

El flamboyán propuesto, aunque posee el aspecto vivaz que interesaba al arquitecto, tiene forma de parasol, un tanto distinta a la copa con ramas ascendentes que dibuja Le Corbusier en la perspectiva ${ }^{42}$. A la postre, sus características morfológicas le habría hecho descartar esa especie, pues su desarrollo horizontal aéreo tocaría la pirámide dada su proximidad, y sus raíces superficiales e invasivas, tal como imaginó Alejo Carpentier en sus Pasos perdidos (1953), aprovecharían “...el descuido de canciones y siestas para arquear el lomo en todas partes, acabando en veinte días con la mejor voluntad funcional de Le Corbusier"43.

La posición de la única presencia natural del conjunto responde, por el contrario, a decisiones matemáticas, a un punto preciso dentro del campo espacial. Su tronco se vería a través del vano enfrentado al acceso de la pirámide, un corte en el volumen resultante de la línea que parte de la esquina noroccidental. Pero también hay otras razones estéticas y funcionales para situar el árbol en el lado oeste del recinto. La principal, proteger a la pirámide del sol de poniente, preocupación del arquitecto por el recalentamiento de la capilla. La otra, es su papel dentro del paisaje interior del recinto. Su vivacidad, es la cara opuesta de la muerte, de la severidad pétrea del muro, del suelo y de la pirámide. Es la forma natural que hace de fondo a la forma geométrica, que proyecta sombras orgánicas sobre el volumen afilado, metálico, escenificando el juego del sol y de los números, de la naturaleza y el hombre.

\section{Epitafio de formas y números}

La tumba de Le Corbusier e Ivonne, con el Mediterráneo al fondo, también es un cuadrado. Una base perfecta, sobre la que reposan dos cuerpos geométricos limpios, puros. Las letras escritas sobre la placa solo aportan datos, el verdadero epitafio son las formas y los números que las generaron. El sol hace hablar a esos números, revelando la belleza y claridad de los volúmenes.

Los trazados reguladores, decía Le Corbusier, son la solución al nacimiento fatal de la arquitectura. El pecado original del desorden, sería purificado por la matemática sensible, dotando a la arquitectura de euritmia, de

\footnotetext{
${ }^{42}$ FLC 33422. El cual usamos en las imágenes del modelo 3D: Figuras 7, 8 y 10.

${ }^{43}$ Carpentier, Alejo, Los pasos perdidos. Madrid: Alianza Editorial, 2002. p.41.
} 
pulso, de vitalidad. La capilla mortuoria de Caracas, estuvo pensada y proyectada bajo esas premisas: formas y números capaces de convertirse en signos.

\section{Procedencia de las imágenes}

Fig. 1. Fotografías de las cuatro primeras láminas del anteproyecto. Archivo de la Fondation Le Corbusier. FLC I2(8)335-003 OFLC-ADAGP; FLC I2(8)335-002 OFLC-ADAGP; FLC I2(8)14 OFLC-ADAGP y FLC I2(8)13. CFLC-ADAGP.

Fig. 2. Cuadro comparativo de las pirámides proyectadas por Le Corbusier, mostrando: Recinto, Caras Abatidas, y Sombras de mañana y tarde respetando su latitud y longitud. Autores: Alayón, Dávila y Graterol.

Fig. 3. Cuadro comparativo de las pirámides proyectadas por Le Corbusier, mostrando: Geometría, relación Base/Altura, y Aproximación /Acceso. Autores: Alayón, Dávila y Graterol.

Fig. 4. Planta de cubierta y trazas reguladoras. Autores: Alayón, Dávila y Graterol.

Fig. 5. Planta baja de la capilla. Autores: Alayón, Dávila y Graterol.

Fig. 6. Alzados este y sur. Autores: Alayón, Dávila y Graterol.

Fig. 7. Vista de la capilla desde el oeste. Autores: Alayón, Dávila y Graterol.

Fig. 8. Vista de la capilla desde el sur. Autores: Alayón, Dávila y Graterol.

Fig. 9. Secciones A y B. Autores: Alayón, Dávila y Graterol.

Fig. 10. Vista de la capilla desde el norte. Autores: Alayón, Dávila y Graterol.

\section{Bibliografía}

Carpentier, Alejo: Los pasos perdidos. Madrid: Alianza Editorial, 2002.

Curtis, William: "Formas sagradas y connotaciones antiguas". En Le Corbusier: ideas y formas. Madrid: Hermann Blume, 1987.

Lapunzina, Alejandro: "La Pirámide y El Muro: notas preliminares sobre una obra inédita de Le Corbusier en Venezuela". Massilia: anuario de estudios lecorbusierianos. Barcelona: Fundación Caja de Arquitectos, 2002, No 2002, pp. 148-161.

Le Corbusier: El Modulor 2. Barcelona: Editorial Poseidón, 1976.

Le Corbusier: Hacia una Arquitectura. 2ª Ed. Barcelona: Poséidon, 1977.

Le Corbusier: Euvre complète 1946-1952. Vol. V. Zurich: Les Editions d’Architecture, 1953. 